\title{
Services for the older adults: a pressing need in the face of an aging population
}

\begin{abstract}
This article is based on new population world tendencies in connection with aging statistics that show that the population in Colombia will increasingly be closer to old age in the future. It also rests on successful aging and resilience to propose entrepreneurial ideas in specialized services and entertainment activities for older adults.
\end{abstract}

Keywords: successful, aging, specialized services for older adults
Volume 4 Issue 4 - 2019

\author{
Omar Cabrales Salazar,' Rafael Martínez \\ Herrera, ${ }^{2}$ Oscar Eduardo Reyes Nieto ${ }^{3}$ \\ 'Economist, Universidad Militar Nueva Granada. Master's \\ Degree in Education and Doctor in Social Sciences, Pontifica \\ Universidad Javeriana. Full time professor, Universidad Militar \\ Nueva Granada. Director of FUVAC, Colombia \\ ${ }^{2}$ Bachelor in Basic Education with Emphasis in English Language, \\ Universidad San Buenaventura. Master's Degree in Education, \\ Universidad Militar Nueva Granada, Professor Universidad \\ Manuela Beltrán, Colombia \\ ${ }^{3}$ Economist, Master's Degree in Quantitative Finance, \\ Universidad Externado de Colombia, Professor Universidad \\ Central, Universidad del Valle, Colombia
}

Correspondence: Cabrales Omar. Economist, Universidad Militar Nueva Granada, Master's Degree in Education and Doctor in Social Sciences, Pontifica Universidad Javeriana, Full time professor, Universidad Militar Nueva Granada. Director of FUVAC, Colombia, Tel 573612132824,

Email omcabrales@yahoo.com.ar

Received: June 24, 2019 | Published: July 02, 2019

\section{Introduction}

According to United Nations projections, ${ }^{1}$ the current global population ( 7.35 billion) will exceed 10 billion in ninety years' time, projecting 9.3 billion by the middle of the century. Agreeing to this variable, the planet will reach 8 billion inhabitants in 13 years' time, 9 billion in 18 year's time, 10 billion in 40 years' time and 11.2 billion in 2100 .

In 1950, five years after the United Nations was founded, global population reached 2.6 billion inhabitants. By 1987, this figure reached 5 billion and, in 1999, 6 billion. In October 2011, there was an estimate of 7 billion inhabitants. To celebrate this historical event, a global movement called "A world of seven thousand million" was created. Lastly, in mid-2015, global population reached 7.3 billion inhabitants which means that this figure has increased by 1 billion. ${ }^{2}$

By the mid-twentieth century, tendencies on global population forecast that very few children will be born in developed countries, and a few more in the formerly called third world. This is to happen if nothing extraordinary occurs regarding the so-called developed or developing country's classification because, as things stand some Latin American and Asian countries, excluding Brazil and India, may overcome the poverty gap and continue to grow economically to eventually become part of the so-called developed countries.

Estimates obtained during the process of census reconciliation for the 1985-2005 period under the 2005 General Census, the 1993 Census, the 1985 Census, vital statistics, and the past three Demographic and Health Surveys (EDS for its Spanish acronym) considering the Colombian population, suggest:

The parameters and indicators by which the dynamics of such components is synthesized maintain the expected tendencies within the demographic and epidemiologic transition process determining the decline in the total fertility rate as well as infant mortality rate, life expectancy increase, and changes in survival probabilities, among others (National Administrative Department of Statistics-DANE. ${ }^{3}$

In this sense, estimates for the Colombian case, according to projections by DANE ${ }^{4}$ suggest that in a few years Colombia's population will increasingly grow older. Projections for 2030 show that the participation of population below 15 years old will be reduced by $17.5 \%, 15$ to 29 years old will be reduced by $4.9 \%$, while population over 65 or older will increase by $35.8 \%$. Over 60 years old they are growing: in 2005 they represented $6.25 \%$ of the population and today they represent $9.23 \%$, that is, almost 4.5 million people. ${ }^{4}$ this tendency is similar in much of the world, especially in Latin American countries such as Chile and México.

As a result of this process, the fertility rate measured through the Global Rate has decreased over the studied period from 3.42 children per woman in 1985 to 2.48 in 2005 . This means that fertility in Colombia has decreased by $27.5 \%$ in the past 20 years. $^{3}$ 
Consequently, it can be said that adult population (aged 60 years or older) in much of the world and in Colombia, both from middle and high class still work despite their being retired or pensioned; a fact that substantially increases their income and makes them subject to be considered potentially consumer-wise. This provides an excellent scenario for the improvement of their quality of life and so reach a peaceful old age. But, for the other side, According to the magazine Dinero. $^{5}$

Undoubtedly, these trends are positive and show an achievement and a radical transformation in the Colombian society. However, they have their problematic side, because there are many questions that are opened about the pressures that the country will suffer from a perspective of public spending on health and the offer of social security, recreation and occupational services for this population.

Therefore, the increase of adult population has created new consumption and business opportunities that may generate substantial employment prospects in Colombia and in those countries that like Colombia already have a developed infrastructure to offer certain kinds of goods that this increasingly growing population segment requires. Likewise, megatendencies aimed at extending youth and the desire to keep a decent quality of life into adulthood have created excellent possibilities and innovative proposals for the people to reach the old age peacefully. In Colombia, when speaking of forest and ocean natural resources in particular there is a wide range of possibilities for the exploitation of new organic products with the feasibility of curing certain diseases and extend youth or, at least, delay or make the ills of old age more bearable.

From this perspective, the first section of this paper develops a brief theoretical framework on the statistical analysis of the Colombian population, current status and projections (2005-2020). The second section discusses the concepts that theoretically support the proposal: successful aging and resilience, both aimed at extending human life with a high degree of welfare. Finally, global experiences from goods and services companies targeting older adults as well as a case study in Mexico are shown.

\section{Statistical analysis of the Colombian population}

Population projections are decisive factors to identify new options to benefit older adults. On the one hand, the most recent census (2018) conducted by DANE presents interesting findings regarding gender and age for the coming years. This, seen as an opportunity, in the good sense of the word, provides data about the needs that older adults will have in the future.

On the other hand, population dimension and projection are of high importance for the State to carry out socioeconomic planning at all levels: national, regional and local. This can be observed in the study conducted by DANE entitled "2006-2020 National and Department Population Projections"

Projections: With this in mind, Colombia starts from a base population equivalent to 45.500 .000 million inhabitants to June 30 , 2018 expected to grow to 46.600 .000 by 2020 . This will be reached starting from a growth rate of 1.25 per every 100 inhabitants in the 2000-2005 period which decreases term after term to reach a 1.09 rate per 100 in the 2015-2020 period.

Both, fertility decrease and life expectancy increase determine a weight reduction for 15-year olds or younger, and the increase of the population aged 64 years or older. In fact, by 2020 weight for children aged below 14 years will reduce by $17.5 \%$, while weight for people aged 65 or older will increase by $35.8 \%$ (Figure 1).

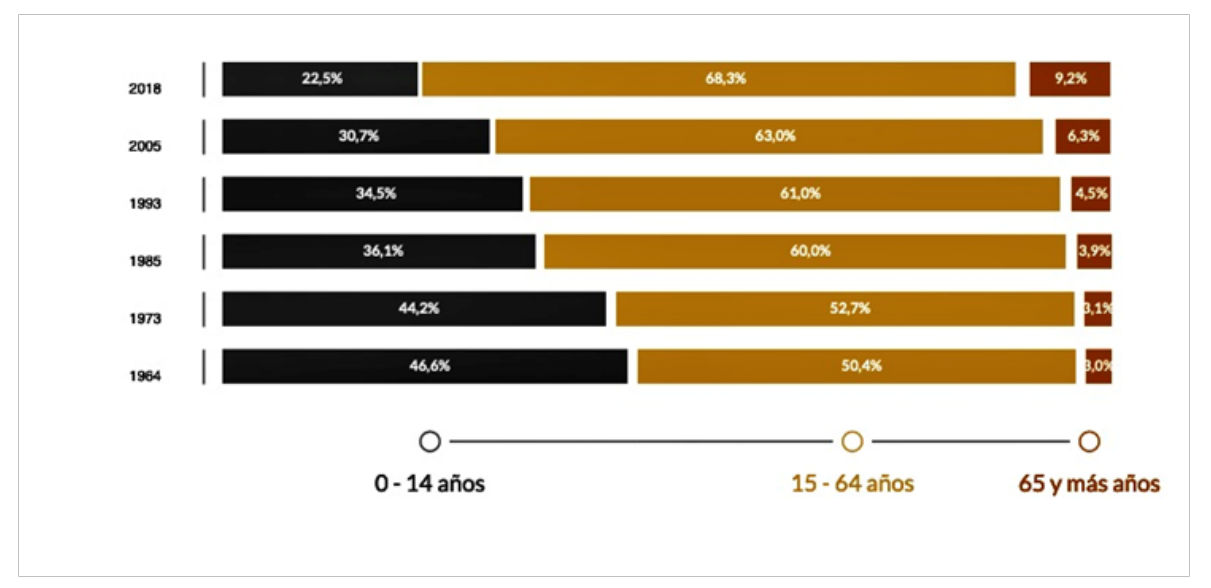

Source Dane. ${ }^{2}$ Population projections 2005-2020

Figure I Distribution of the population by large age groups 1964-2018.

The data above shows that the aging process is already affecting the Colombian population. This determines the need to realign State policies with the changes in population dynamics and calls the attention of the productive sector to consider the data shown within their projections and actions.

This event compels us to talk about an aging population and take the required measures to guarantee such a population not only a decent quality of life but also the possibility to engage in paid and leisure activities that contribute to their development, welfare and also, the country's economic progress.

\section{New tendencies in services for older adults}

As discussed before, the characteristics of population growth are changing, the tendency is already set, and the life is then adjusting. The way to perceive older adults is changing as other tendencies like vegetarianism, veganism, new couple models, and others brought about by new generations are. According to Yuval Noha, ${ }^{6}$ in the twentieth century we practically doubled life expectancy, which went from being 40 to 70 years, so that in the 21 st century we should be able to, at least, double it again, until 150 years. This will revolutionize human society. 
The world is adjusting to new and old generations as well; older adults are asking for a change of paradigm. In their pursuit of keeping and looking young, for instance, older adults ask for new goods and services that rebuild their human condition with equal rights; labor market, education, and services inclusiveness. According to Correa and Bohórquez. ${ }^{7}$

Entertainment, surgeries, specialized tourism, anti-aging products, and investment property projects in coastal cities comprise the range of possibilities for older adults. They are the preamble for a millionaire industry increasingly expanding in Colombia. The most recent report by the World Health Organization on the global pace of population aging is conclusive: by 2050, 400 million people aged 80 years will inhabit the planet (p. 32).

There are already companies in Spain, Canada, the United States, Mexico, and Chile engaged in providing these services, companies that have gradually discovered the demands and needs of this population segment. Older adults are not considered a burden in these countries any longer; their economic potential is a key factor to exploit since their vision of the world and their saving capacityproceeding from their income in times when it was easier to build capital-derives from times when saving and consumption were not people's main purpose in life. According to Enrique Vega, the Pan American Health Organization (PAHO) regional adviser: "the twentieth century shows a true longevity revolution. In only a few decades, human life expectancy increased by almost 30 years" (S.f, p. 6).

Tendencies have led businesspeople to identify the need to start companies engaged in providing entertainment services to these longer-living people and thus understand the importance of opening spaces for older adults to do what they like. This, since their intense experience accumulated over the years gives them the right and authority to really have what they want, not what the market offers or what their children or grandchildren impose. Furthermore, older adults are not subject to the evolution of fashion and tendencies that do lead the volatile spirit of today's youth. In fact:

Age is being reinterpreted, a sort of countdown. Regression is a way to reconsider the appropriate behavior for each age. It is a new unprecedented cultural phenomenon that longevity poses. ${ }^{8}$

For several decades, older adults have defined themselves as an interesting segment with growth possibilities. They are a new and barely explored segment with many benefits with important purchasing power. "In the U.S., people aged over 50 years spend 1.7 billion dollars in products and services every year, almost half of the consumption of the country" (Arbiser, 2006).

It is also important to consider that this is a complex population that is often seen from a different stance. For this reason, their way of thinking, cultural heritage, education, entertainment and working ways, course of time and emotions must be paid attention to so that they are provided with alternatives that improve or, at least, maintain the quality of life they have had over the years.

Undoubtedly, the opportunities for older adults to improve their quality of life are growing. The world must understand it right now since this transformation will be decisive and will create new spaces to achieve resilience and experience their growing old as an enjoyable stage of their lives. Issues such as commuting and mobility, health and physical welfare, leisure, entertainment and saving aimed at assisting and supporting older adults are becoming important, too. In the future these issues will increase the demand for palliative and preventive medicine; the tourist sector will focus on meeting their needs: gyms, cinemas, magazines, nutritional supplements, vitamins and organic foods to prevent disease and promote longevity; machines and products to do sports and have fun at home, biomechanical prostheses, and virtual reality are some of the ideas that may bring comfort to the old age and so, contribute to positively adapting to the challenges that age will bring.

\section{Successfull aging and resilience}

This section will discuss some tendencies that have had a positive effect on the creation of a new science that turns out to be extremely useful to argue for the needs and rights for older adults. Positive psychology, a discipline that has evolved over the past 20 years, proposes the psychology of the human potential as a theoretical and psychological alternative to urge humankind to foster inner growth and all its capabilities. This type of studies emerged in the mid1990s as a result of investigations by P Baltes et al. ${ }^{9}$ who associate the development of human capital with the concept of wisdom and optimism, personality growth, resilience, altruism, successful aging and the positive aspects of human functioning, among others.

In any case, the emergence of this new discipline has brought about concerns and objections by clinical psychologists. This, since the psychological studies have focused more on repair pathology than on investigating the positive aspects of welfare and health.

One of the reasons for approaches in healing and repair psychology to have historically prevailed may come from a matter of values. It is much easier to define the desired adaptive direction for change if the aim of such a change is to restore a normal or previous mode. On the other hand, it is much more difficult to define human potential if the psychological changes are considered over the return to previous functioning levels. ${ }^{10}$

In fact, attempting to take the human body and mind to upper levels in which they can project and heal themselves is a little more complex than bringing them back to normality, even when such normality has been characterized by episodes of crisis, loneliness, depression, stress, and other syndromes.

Aging is a universal process affecting all species. In our case as humans, aging affects us in a specific way since we are aware of this condition for it means deterioration and diminishment ending up in death. ${ }^{11}$

In the information and knowledge, Artificial Intelligence and Big Data society in which young people have higher deterrence and show their lifestyle through social networking, older adults have underestimated their ways describing them as outdated and useless, vindicating a physical appearance-based model of beauty, youth and consumption $^{12}$ that increasingly excludes older adults from a society they have the right to live in.

On the other hand, while the general view of adulthood was maturity, and growing up to becoming an adult was taken for granted, it is now understood as another step ahead in life characterized by transition to later stages. " "However, the goals and contexts of human development are more complex, dynamic and variable than these traditional views based on specific definitions of domains or suggested by the final states." (Baltes \& Freund 2007, p.47). Final states need to be considered as the past stages that people would consider in their 
path to adulthood. They need to be a possibility to overcome different stages in life so that maturity is reached successfully. ${ }^{13}$

Progressively considering the fact of closeness to death and feeling the gradual reduction of brain and body functions in comparison with what youth provided, makes people lose their sense of life and become depressed in the last period of their existence. From the perspective of successful aging, this requires more attention and care, thus generating an opportunity to satisfy the needs of this segment of the population.

While people now live longer as a result of science and medicine, particularly in developed countries, this life extension may come at the expense of old and disabled people as a result of diseases affecting their physical and/or mental health. So, living longer, living a much longer life does not necessarily imply living well. Hence, the discussion of what it means to grow old well arises in response to this situation. ${ }^{11}$

From this point of view, there are various concepts such as optimism, resilience and successful aging ${ }^{14-17}$ introduced by John Rowe ${ }^{18}$ which have permitted to view the aging process in a different way compared to the traditional one that considers aging as a progressively irreparable deterioration of the body and mind functional capabilities which, in turn, explains why older adults feel the need of being still productive, loved and successful under their specific conditions which, in fact, are different from those of youths, thus requiring a more inclusive view. "Young people and older adults compare each other, and in case of differences, the situation gets worse. This-leads to the sense that when people grow old - and we all do - they anticipate their decline." 19

Consequently, we start from the notion that comparisons in this sense do not improve life conditions for older adults but jeopardize them since the prevailing comparison model of the western world where beauty, fresh skin, and youth are a prerequisite to achieve happiness and success. We live in a world that sees youth and physical beauty as ascending values, one which defames aging and dismisses more promptly the old and the outdated. Besides a generation gap, there is an insurmountable technological gap since today's older adults were born and grew up in an analog world radically different from the one young people are experiencing; where notions of time, happiness, and progress were tied to conservation values rather than to continuous and sudden changes. ${ }^{20}$ According to Capella, ${ }^{21}$ these cultures are «based on tradition». Those living in such cultures know «what has always been». Memories are stabilizing, thus restoring the past into the future. The future is seen both with hope and fear; therefore, older adults feel not only excluded but also threatened.

Consequently, today's world should be regained as an inclusive one for all. Mainly if we understand that today's youth will grow old someday. A world in which older adults, with a growing purchasing power, are also part of it. So, consumption parameters and happiness conditions must be changed or, at least, adjusted to include these people. Starting from the same comparative model, it should be mentioned that older adults lose skills and abilities over time but gain others that are impossible for the youth. This is what successful aging is about generating the conditions for a good socioeconomic level-; relatively low body weight; good lung function; good cognitive performance; free from diabetes and high blood pressure; and active engagement in educational, physical and social activities. It is decisive to take aging positively and consciously as well as to understand that what is left behind is irreversible without longing for and extremely desiring the pleasures of youth. It is also crucial to take it with courage, honesty and full knowledge that aging is not dying and that it also offers many advantages over the years. According to Castillo, ${ }^{11}$ successful aging comprises the following factors:

a) Low probability of disease and disease-related disability. This refers to the reduction of the possibility of getting sick over the years as a result of early awareness of the dangers brought about by the excesses of the youth and lack of prevention against those factors causing disease and the progressive deterioration of vital body organs. This is about keeping a balanced diet, avoiding stress, doing any type of sports or physical activity, refraining from smoking or drinking alcohol in excess, avoiding sun rays, and visiting the doctor regularly, among other things.

b) High cognitive and physical functional capacity: certain type of disabilities related to skin, eyesight, muscle and tendon elasticity that hinder mobility and agility come with old age, which does not mean that activity should be limited at all. Living implies being active, doing something, building something, devising something; every living organism must be active and adapt or else would die out. For this reason, physical activity at home or outdoors is so important for it prevents people from confinement and isolation to the point of stop longing for contact with the world.

As for the brain, it is not true that this organ becomes useless since it starts to incorporate and work to the accumulated experience over the years. This is something young people just cannot do. To Carlos Cano, a doctor of geriatrics at Fundación HETAH (S.f), ${ }^{22}$ who has studied the cognitive skills of older adults, it is wrong to consider that the brain gradually becomes inoperative at this stage of life; what really happens is that the brain reorganizes favorably most of the times. To prove this, older adults use areas of the brain inactive in young people to carry out certain tasks.

Recent investigations conducted with functional brain images (including positron emission tomography) have drawn conclusions against the myth claiming that cognitive functions deteriorate over the years.

These studies also claim that the brain in older adults works under other parameters. It has been observed, for example, that these people use both frontal lobes instead of the left one only (as young people do) during everyday activities like shaving or driving a car. ${ }^{22}$

c) Active engagement with life: the three elements mentioned above are of relative importance, but engagement with life is the one that gives the most meaning to the notion for it is closely connected to the notion of meaning in life. According to Aristotle, life shall be oriented towards something meaningful; it is about giving it a purpose, a goal for life is not a value itself.

Psychology and science both have analyzed the problems arising from old age leaving out their benefits and potential. Youth is related to good things while old age to deterioration, disease, and negativism. Consequently, it is necessary to positively and openly appraise the resources, work experience, wisdom and emotional experience, among others, offered by older adults. Because of this, resilience, understood as the capacity human beings have of succeeding in difficult times and great losses, comes into play. Through experience and over the years, older adults are capable of overcoming obstacles and the absence of their loved ones and forge a better future. Endurance is much needed to achieve resilience; older adults have it, though. They have the 
capacity to take great failures and losses; they are experienced and mature and should be treated accordingly. Hence, older adults are human beings and should be respected; their limitations and skills must be considered for they are still part of the human community.

After briefly defining the new perspectives of successful aging, a list by category including the different likely goods and services to be offered in Colombia must be drafted to provide potential investors and businesspeople with insights regarding market research for some or various of these products.

i. Health-related goods and services: psychology and geriatric medicine (preventive and palliative) that may include genetic and molecular interventions, specialized medical treatments, home care, nursing, gyms, aerobic activity, training, technology appropriation courses, various courses (painting, yoga, etc.), education for older adults.

ii. Finance-related goods and services: consultancy on business plans, credits, accounts, credit cards, and special financial service portfolios' preparation and implementation.

iii. Legal counseling: legal counseling to help older adults to solve problems in the field of civil, family and other legal specialties. Also, provide them with administrative support before different bodies to ensure that their requests are managed promptly and even help them with bank, legal, notary and State formalities.

iv. Basic activities and/or living conditions-related goods and services: removal of architectural barriers, home maintenance and cleaning, specialized transport, courier services. This includes a range of special products for adequate housing conditions to be installed; for example, elevators, slip-resistant flooring, carpets, motorized wheelchairs, special kitchens, alarms, bathroom vanities (veneers), windows, stairs, TV cameras, etc.

v. Instrumental activities: personal welfare in terms of cultural survival: joining a social club, various community or charitable organizations (volunteering their work), doing self-enriching and inclusive activities leading to their social development, thus keeping a life full of active contacts with counterparts or younger people.

vi. Entertainment activities: specialized travel agencies, recreational home activities, partner/peer reading, group walks and visits, home entertainment products.

vii. Technology: counseling on social networking, video and photography, Skype, IoT, TVs and smart phones with special remote controls and few keys. Apps designed to help people who suffer from dementia, Alzheimer and other diseases, games, etc. Here is a list of the most useful applications for older adults according to Forbes (2018): Medication (time and administration): something very common in older adults searching for independency is that they are taking medications but frequently forget to take it and skip the dose. Thanks to certain automatic dispensers it is possible to take medication on schedule.

Continuous health monitoring: older adults seeking the highest independence possible must cope with continuous incoming calls from relatives to make sure everything is going well. Machine learning algorithm-based sensors and devices help older adults detect changes in activity levels that may arise from risky events.
Safety and control: for those who constantly battle with mobility issues, there are remote-controlled solutions to operate equipment. Be it a stove, a microwave, a heater, etc., they can be remotely activated without making the person stand up or move at home. There are even voice-controlled devices on the market.

viii. Language-learning activities: thanks to real-time Internet communication and built-in webcams, older adults may contact young people and teach their native language pronunciation and grammar. This activity approaches generations and keeps older adults active and motivated while preparing their classes and conversations.

\section{Conclusion}

There are various services for older adults in Colombia. Among these we can find nursing homes that, in many cases, do not comply with the legal standards established for the care of people aged 60 years or older. Regarding recreation, sports and leisure activities, compensation funds have led this aspect offering different programs for the pensioned.

In Colombia, there are almost no companies devoted exclusively to offering comprehensive services for older adults. Some NGOs assisting older adults in some regions of the country, mainly vulnerable senior population, are worth mentioning. These organizations seek to provide older adults with a decent quality of life, thus positively affecting their daily lives through favorable spaces for participation and inclusiveness. All this to offer comprehensive well-being for older adults as far as housing, food and primary health care services are concerned.

Regardless of their economic capacity, the offer for middle- and high-class older adults is not very broad since they can only choose from various nursing homes that sell basically the same services. Despite the great offer of nursing homes, private companies do not furnish any novelty services to promote an active old age, but, on the contrary, the notion of almost completely diminishing older adults is the common mode.

Recreation and entertainment services are mainly centered on compensation funds or mutual organizations since they have the infrastructure and personnel required for specific programs. These organizations schedule workshops of all types, national and international travels, concerts, plays, and agreements with specialized institutions, for example, gyms, and spas, among others.

In Bogotá, the Instituto Distrital de Recreación y Deporte (Institute for Recreation and Sports) and the Coordinación del Programa Tercera Edad (Office for Older Adults) and some foundations like: FUVAC (Foundation for the community advance), ${ }^{2-34}$ are engaged in comprehensively assisting older adults through their active participation in recreational activities and sports so as to maintain, promote, and improve their physical, emotional and social conditions emphasizing the good use of parks and the role of older adults as the main actors of their own personal, family and community development.

The world and the Colombian population will progressively grow older and private companies and the State must be prepared to cope with the necessary changes to offer this segment of the population all the attention they require to cover their needs. To this end, families 
need to work within and change the notion of older adults as a burden and that they merely deserve to be sent to nursing homes with poor conditions. Older adults must be treated in an inclusive manner; their needs must be observed, and their rights respected. It is necessary to revendicate this stage of life as a productive and quiet period worth living.

To achieve a peaceful and successful old age, people must consider that need of inclusiveness and respect that older adults deserve. The Colombian society needs to understand that just like any other member in the society; older adults need attention, affection and care. They need spaces for leisure, to be busy with different tasks to challenge the crisis and fears that the process of aging brings. In this regard, to avoid deterioration and provide a healthy environment for them to reach a new stage of life peacefully, specific studies and research must be conducted to clearly define the demands of this population and so, design plans to meet their needs.

Older adults not only seek retreat locations; they also want to travel, study, share, be heard and valued as well as continue living at home surrounded by specialized personnel guaranteeing a decent quality of life. The State and private companies must provide older adults with adequate training that allows them to get employed by performing tasks consistent with their condition, for example, employees, consultants or advisers. Organizations for older adults must strengthen in such a manner to actively participate in the design of public policies and take part through the mechanisms offered by the State.

The participation of older adults in the design and implementation of regional and departmental projects must be promoted as they may stress, based on their experience, the strengthening of citizen competencies and democratic processes, the reduction of social exclusion, and the improvement of their quality of life.

To sum up, a new positive, motivated, hard-working and committed culture and image of old age must be disseminated considering the most recent studies on positive psychology, successful aging, and resilience. Parents and even children need to strengthen the collection mechanisms for mandatory and voluntary pension schemes to ensure the resources to provide older adults with a decent quality of life and human development.

\section{Acknowledgments}

Research: Andragogy and human development. Cod: AN-1901. FUVAC: Foundation for Community Advancement.

\section{Conflicts of interests}

Authors declare that there is no conflict of interest.

\section{References}

1. United nations - UN. World population prospects; 2010.

2. http://www.un.org/es/sections/issues-depth/population/index.html

3. https://www.dane.gov.co/files/investigaciones/poblacion/ proyepobla06 20/7Proyecciones poblacion.pdf

4. http://www.dane.gov.co/index.php/estadisticas-por-tema/demografia-ypoblacion/censo-nacional-de-poblacion-y-vivenda-2018

5. https://www.dinero.com/pais/articulo/cuantos-colombianos-estan-en-latercera-edad-segun-el-censo/261611

6. Noah, Yuval. Homo deus. homo deus: A brief history of tomorrow. Harper Collins Publisher; 2017.

7. http://www.facso.uchile.cl/observa/espectador mercado.pdf
8. http://www.alimentosargentinos.gov.ar/contenido/procal/estudios/01/ TendenciasConsumoAlimentos.pdf

9. Baltes P, Staudinger U. Wisdom: A metaheuristic (pragmatic) to orchestrate mind and virtue toward excellence. The American Psychologist. 2000;55(1):122-136.

10. Aspinwall L, Staudinger U. A Psychology of human strengths: fundamental questions and future directions for a positive psychology. Washington DC. American Psychological Association; 2013.

11. Castillo D. Envejecimiento exitoso, en revista de medicina clínica. Clin Condes. 2009;20(2):167-174.

12. Cabrales O, Márquez F. El buen vivir y el no consumo como modelos de desarrollo desde la perspectiva de la bioética global. Revista Latinoamericana de Bioética. 2016;17(1):168-183.

13. Cabrales O. Martínez R. Bermúdez. Playing and creativity as pedagogical strategies to face the new challenges of education in Colombia. Science Journal of Education. 2017;5(6):244-251.

14. Birren JE. The psychology of aging. Englewood Cliffs, NJ: Prentice-Hall; 1964.

15. Butler RN. Successful aging and the role of the life review. Journal of the American Geriatrics Society. 1974;22:529-535.

16. Pressey SL, Simcoe E. Case study comparisons of successful and problem old people. Journal of Gerontology. 1950;5:168-175.

17. Naresh K. Investigación de mercados: Un enfoque práctico. Editorial $A$ Simon a Scheuter Company. 2000.

18. Rowe JW, Kahn RL. Successful Aging. The Gerontologist. 1997;37(4):433440 .

19. Carstensen L, Charles S. Psicología del potencial humano. Editorial Gedisa. España. 2007.

20. Cabrales O. La aceleración del tiempo en relación con la idea de progreso y la crisis del trabajo. Entramado. 2012;8(2):106-122.

21. Capella J. El tiempo del progreso. Conferencia correspondiente al ciclo sobre la modernitat organizado por el centre d'estudis de temes contemporanis de la generalitat de catalunya. Barcelona; 1990.

22. http://www.hetah.net/old/modules/newbbex/viewtopic. php?viewmode $=$ thread\&topic_id $=390 \&$ forum $=33 \&$ post_id $=2008$

23. FUVAC (Foundation for the community advance).

24. http://www.agermexico.com/index.html

25. Cabrales O. Productos y servicios para los adultos mayores, un potencial nicho de mercado en Colombia. Dimens Empres. 2013; 11(1):103-115.

26. Inapam. Informe de rendición de cuentas de la APF 2006-2012. rendicion de cuentas, Ciudad de México; 2012

27. http://www.inapam.gob.mx

28. Kotler P. Dirección de marketing conceptos esenciales, Primera Edición. Prentice Hall; 2002.

29. https://www.medellin.gov.co/amauta/archivos/Resolucion Nac 7020 1992.pdf

30. http://www.constitucioncolombia.com/titulo-2/capitulo-2/articulo-46

31. http://www.villazul.com.mx/default.aspx

32. https://www.forbes.com.mx/tecnologia-inteligente-para-los-adultosmayores/

33. https://crearunaempresaya.wordpress.com/2012/08/31/aspectos-a-teneren-cuenta-al-hacer-el-estudio-de-mercado/

34. http://www.riicotec.org/InterPresent2/groups/imserso/documents/binario/ amgvega.pdf 